\title{
우리나라 생태산업단지 구축사업의 추진전략과 성과평가 Assessment of Strategy and Achievements of Eco Industrial Park (EIP) Initiative in Korea
}

\author{
박준모* · 김형우** · 박흥석**** \\ Jun-Mo Park* $\cdot$ Hyeong-Woo Kim** $\cdot$ Hung-Suck Park $* * *^{\dagger}$ \\ *울산대학교 건설환경공학과 - **한국산업단지공단 울산EIP사업단 \\ *Department of Civil and Environmental Engineering, University of Ulsan \\ **Dongnam Regional EIP Project Division, Korea Industrial Complex Corp.
}

(Received November 6, 2014; Revised November 18, 2014; Accepted November 26, 2014)

\begin{abstract}
This study assesses the strategy and performance of Eco-industrial Park (EIP) initiative implemented by Korea Industrial Complex Corporation (KICOX) with the support of Ministry of Trade, Industry and Energy (MOTIE), Korea since 2005 to 2013 and recommends future directions. After the concept of EIP based on industrial symbiosis (IS) is introduced, the background and implementation procedure of the EIP initiative are described. Then, economic and environmental achievement was assessed. During the project periods (2005-2013), 449 industrial symbiosis project were explored, among which 296 projects have been implemented. Among (Of these 296 projects,) them, 244 projects have been completed in which 118 projects have been commercialized which shows $48 \%$ commercialization rate of the completed projects. Through these commercialized projects, around 311.1 billion won/year of economic benefits and reduction of waste $\cdot$ by-products of 828,113 tons/year, wastewater of 215,517 tons/year, reduction in energy consumption of 250,475 toe/year and GHG emission reduction of 1,107,189 $\mathrm{tCO}_{2} /$ year were achieved. This results confirmed that EIP initiative based on industrial symbiosis can enhance eco-efficiency of industrial parks and harmonize economy and environment. However, there are obstacles like absence of interagency coordination and cooperation, laws and institutional barriers, increased demand for local governments, funding for project investment. Thus, to utilize EIP initiative as a strategic tool for competiveness and environmental management of industrial parks, it needs intergovernmental collaboration and interdisciplinary approach to lower barrier in implementation.
\end{abstract}

Key Words : Development Project of Eco Industrial Park, Strategy, Economic Achievement, Environmental Achievement, Evaluation

요약 : 본 연구는 국내에서 2005년부터 산업통상자원부에서 산업단지의 환경을 개선하기 위하여 추진하여 온 생태산업단지 구축사업의 전략과 경제적/환경적 성과를 정량적으로 평가하고, 향후 발전방향에 대하여 고찰하였다. 우선 산업공생에 기반 을 둔 생태산업단지의 개념을 소개하고, 국내 생태산업단지의 추진배경과 사업수행절차에 대하여 설명하였다. 또한 산업공 생 사업의 전후의 경제적, 환경적 성과평가 방법론을 제안하고, 사업화된 과제를 대상으로 성과평가를 실시하였다. 우리나라 생태산업단지 구축사업은 한국산업단지공단이 주관하여 현재 전국에 9 개 지역사업단을 운영 중에 있다. 2005년부터 2013년 까지 449 개의 아이템을 발굴하여 296 개가 선정되어 수행되었으며, 이 중 244 개의 과제가 완료되었다. 완료된 과제 중 118 개 의 과제가 사업화되어 사업화 성공률이 약 $48 \%$ 로 나타났다. 사업화된 과제를 통하여 약 $3,111.1$ 억 원/년의 경제적 효과와 폐기 물/부산물 828,112.6톤/년, 용수/폐수 $215,517.0$ 톤/년, 에너지 $250,474.5$ toe/년, 온실가스 $1,107,189.1 \mathrm{tCO}_{2} /$ 년의 사용 및 배출을 저감하는 환경적 효과를 얻었다. 이상의 결과로부터 산업공생 원리를 이용하한 생태산업단지 구축사업은 산업단지의 생태효 율성 향상으로 환경과 경제를 조화시킬 수 있음을 실질적으로 확인시켜주었다. 하지만, 관계 부처 간 협조와 협력의 부재 및 법과 제도적 한계, 지방자치단체의 요구 증대 및 기업체의 자금문제 등의 장애요인이 존재한다. 따라서 생태산업단지 구축사 업이 지속가능한 산업단지 모델로 전국적으로 확대되고, 산업단지 경쟁력 강화와 환경관리를 위한 툴로 발전시키기 위해서는 현재의 장애요인을 해소하기 위한 범부처적, 학제적 접근이 필요함을 보여주었다.

주제어 : 생태산업단지 구축사업, 전략, 경제적 성과, 환경적 성과, 평가

\section{1. 서 론}

최근 산업발전에 의한 화석연료와 자원의 대량생산과 소 비는 지구온난화, 오존층 파괴, 해양오염, 산성비와 같은 지 구환경 문제뿐만 아니라 에너지 및 자원고갈로 인류 공동의 문제를 야기한다는 인식이 확산되면서 지구차원의 대책도 구체화되어 가고 있다. 이미, $\mathrm{UNCED(1992)와} \operatorname{WSSD}(2002)$ 등과 같은 환경정상회의에서 지속가능한 발전을 위해 기후 변화협약 및 생물 다양성 협약 등과 같은 국제환경협약이
체결되면서, 지속가능한 발전을 저해하는 산업 활동에 대한 직간접 환경규제가 강화되거나, 더 나아가 경제 통상활동을 제한하는 무역규제 방향으로 진행되고 있다.

이와 같은 대내외적 환경규제는 기업 활동의 목표를 자 원소비와 생산의 극대화에서 자연계의 한계 내에서 지속가 능한 발전을 이룰 수 있도록 생산과 삶의 질을 극대화하는 방향으로 전환시키고 있다. 따라서 많은 기업들이 환경경영 의 도입, 환경설비 투자 확대, 환경문제에 대한 기업의 사회 적 책임강화 등 친환경 기업으로 이미지 개선을 적극적으로 
추진하고 있다. 또한, 자원과 에너지의 효율을 제고화기 위하 여 자연생태계의 공생원리를 산업계에 적용된 산업공생 개 념 $^{1}$ 이, 덴마크 칼룬버그 사례 ${ }^{2}$ 를 통해서 알려지면서, 기업 간의 협력을 통해 산업단지 차원의 자원 및 에너지 효율을 향상시키기 위한 노력도 전 세계적으로 확산되고 있다.

생태산업단지(eco industrial park, EIP)는 '환경친화적 산 업구조로의 전환촉진에 관한 법률' 제 2조 6 항에 생산과정 에서 발생되는 폐기물, 부산물, 에너지 등을 산업공생네트 워크를 통해 재자원화 혹은 재이용하거나, 이들을 순환 이 용할 수 있는 생태적 기반시설을 조성함으로써 환경에 대한 부담을 최소화하고 자원 효율성을 극대화하기 위하여 지정 된 산업단지로 정의 ${ }^{3)}$ 하였다. 생태산업단지는 신규산업단지 의 개발, 기존산업단지의 생태산업단지화 및 노후 산업단 지의 개발 등에 적용되어 다양한 시범사업들이 전 세계적으 로 이루어졌으며, 많은 사업들이 계획되고 있다. 특히 유럽, 미국, 일본 등의 선진국들은 신규산업단지의 설계단계부터 생태산업단지 개념을 도입하는 사례가 늘어나고 있으나, 생 태산업단지의 건설은 아직 시작단계라고 할 수 있다. 한편, 기존산업단지에서 산업공생네트워크를 구축하여 생태산업 단지로 전환하는 작업은 90 년대 후반부터 진행되었음에도 성공한 생태산업단지 사업은 많지 않은 것으로 알려져 있 어, 생태산업단지 구축사업을 추진하는 것이 매우 어려운 일 임을 암시하고 있다.

우리나라에서는 환경부가 '지속가능한 개발을 위한 생태 산업단지 구축방안 ${ }^{4)}$ 에 대하여 연구를 하였으나, 후속 사업 을 추진하지 못하였다. 그러나 산업통상자원부가 산업단지 의 자원 및 에너지 효율향상을 통한 환경문제 해결과 산업 단지의 경쟁력 제고를 목표로 2005년부터 3단계 15년(2005 년 2019년)에 걸친 생태산업단지 구축사업을 계획하여 추진 하여 왔다. 시범사업으로 추진된 1단계 사업(2005년 2009 년)은 울산, 경북(포항), 전남(여수), 경기(반월·시화), 충북 (청주)의 5 개 시범단지를 대상으로 5 년간 추진되었다. 2 단계
사업(2010년 2014년)은 기존의 5개 지역에 4개 지역(부산, 대구, 전북, 충남)을 추가하여 총 9개 지역을 대상으로 $\mathrm{Hub}$ and Spoke 방식으로 추진하면서 산업공생 네트워크를 확산 시키고 있다. ${ }^{3 \sim 5}$ 우리나라 생태산업단지 구축사업은 R\&BD 방식으로 추진되어 2005년부터 2013년까지 9년간 수행된 구축사업을 통해 총 118 개의 산업공생 사업이 연구 후 사업 화되어 높은 경제적 및 환경적 성과를 거두었다. 이와 같은 성과를 통해 한국의 생태산업단지 구축사업은 국제기관, ${ }^{5,6)}$ 국외 학계와 산업계에서 많이 연구 ${ }^{5,712)}$ 되고 있으나, 국내의 환경 분야에서 생태산업단지 구축사업에 대한 연구 ${ }^{13215)}$ 가 미진한 실정이다.

본 연구는 우리나라 환경계의 기여가 크게 요구되는 생태 산업단지 구축사업의 활성화와 발전 방향을 모색하고자 생 태산업단지 개념과 환경적 및 경제적 성과 평가방법을 제안 하였다. 또한, 우리나라 생태산업단지 구축사업의 계획과 추 진전략을 요약하고, 산업공생 네트워크 발굴 및 사업화와 사 업화를 통한 경제적 및 환경적 성과를 평가하였으며, 사업의 확대를 위한 발전 전략을 제안하였다.

\section{2. 생태산업단지 개념과 성과평가 방법론}

\section{1. 개념}

생태산업단지는 산업공생을 기초로 한 산업생태학의 개념 을 도입하여 청정생산이 되도록 설계, 개발, 운영하는 산업 단지를 말하며, 이는 산업단지 내 기업과 기업, 기업과 공장 또는 공장과 공장의 생태학적 연결을 통하여 물질 및 에너 지의 사용과 오염물의 발생을 최소화하는 유기적 관계로 구 성된 산업단지이다(Fig. 1). Fig. 1은 산업단지내의 세 회사 간의 자원 $(\mathrm{R})$ 과 폐기물 $(\mathrm{W})$ 간의 산업공생을 보여주고 있다. 각 회사는 외부에서 들어오는 자원 $\left(\mathrm{R}_{\mathrm{E}}^{\mathrm{i}}\right)$ 과 산업공생 구성원 간의 자원 $\left(\mathrm{R}_{\mathrm{I}}^{\mathrm{i}}\right)$ 을 이용하여 제품 $\left(\mathrm{P}_{\mathrm{E}}^{\mathrm{i}}\right)$ 을 생산하고, 외부로 배

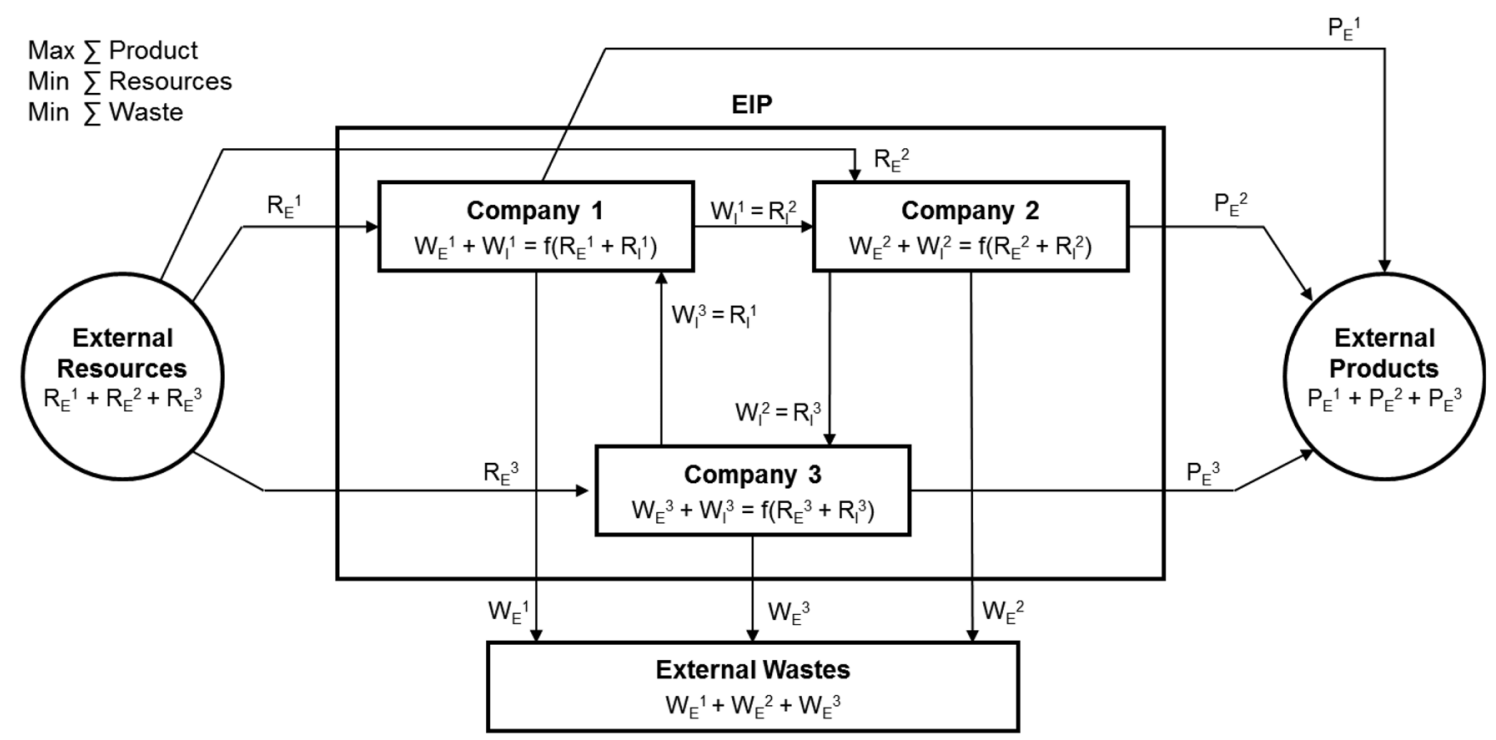

Fig. 1. Conceptual diagram of the EIP., ${ }^{5,18)}$ 
Table 1. Comparison of the conventional industrial park and the EIP $^{25)}$

\begin{tabular}{|c|c|c|}
\hline Classification & $\begin{array}{l}\text { Conventional } \\
\text { industrial park }\end{array}$ & Eco industrial park (EIP) \\
\hline Criteria & Economic benefit & $\begin{array}{c}\text { Economic and environmental } \\
\text { consideration }\end{array}$ \\
\hline Network & $\begin{array}{l}\text { Focused on raw } \\
\text { material, products }\end{array}$ & $\begin{array}{l}\text { Focused on raw material, pro- } \\
\text { ducts, by-products, waste heat }\end{array}$ \\
\hline Waste disposal & $\begin{array}{l}\text { Disposed by } \\
\text { individual or groups }\end{array}$ & Reuse and recycle \\
\hline Waste generation & Large quantity & Minimal/Zero quantity \\
\hline Social image & Causes pollution & Eco-friendly industry \\
\hline Community & $\begin{array}{l}\text { Environmental } \\
\text { conflict }\end{array}$ & Community friendly \\
\hline
\end{tabular}

출되는 폐기물 $\left(\mathrm{W}_{\mathrm{E}}^{\mathrm{i}}\right)$ 과 산업공생 구성원 간에 이용되는 폐기 물 $\left(\mathrm{W}_{\mathrm{I}}^{\mathrm{i}}\right)$ 이 발생된다. 여기서 회사 1 로부터 배출된 폐기물 $\left(\mathrm{W}_{\mathrm{I}}{ }^{1}\right)$ 은 생태산업단지의 경계 내에서 거래되는 회사 2 에 자원 $\left(\mathrm{R}_{\mathrm{I}}{ }^{2}\right)$ 으로 활용되고, 결국 산업단지의 영역 안에서 폐기물 $\left(\mathrm{W}_{\mathrm{I}}^{\mathrm{i}}\right)$ 은 다른 회사의 자원 $\left(\mathrm{R}_{\mathrm{I}}^{\mathrm{i}}\right)$ 으로 이용된다. 이러한 폐기물의 자원 으로 활용을 통해 총 폐기물 배출량 $\left(\mathrm{W}_{\mathrm{E}}{ }^{1}+\mathrm{W}_{\mathrm{E}}{ }^{2}+\mathrm{W}_{\mathrm{E}}{ }^{3}\right)$ 이 감 소하고, 총 자원사용량 $\left(\mathrm{R}_{\mathrm{E}}{ }^{1}+\mathrm{R}_{\mathrm{E}}{ }^{2}+\mathrm{R}_{\mathrm{E}}{ }^{3}\right)$ 은 절감될 수 있다. ${ }^{5,18)}$ 따라서 생태산업단지의 산업공생은 산업단지의 생태 효율을 증가시킬 수 있다.

그러므로 생태산업단지는 물질 및 에너지의 교환을 통하여 생산을 최대화하고 자원 및 에너지의 소비와 폐기물의 발생 을 최소화하는 것을 목적 ${ }^{16,17)}$ 으로 신규 산업단지의 건설뿐 만 아니라 전통 산업단지의 경쟁력 제고에도 활용되고 있다. 전통적인 산업단지와 생태산업단지를 다양한 측면에서 비교 하여, 차이를 정리하면 Table 1과 같이 요약할 수 있다.

따라서 생태산업단지는 기업들의 단독 환경개선활동 보 다 더 많은 경제적 및 환경적 효과와 생산성 향상을 얻을 수 있으며, 생태산업단지 구축을 통해 산업단지는 물론 기 업과 지역사회, 종업원과 주민이 융화되는 지속가능한 발전 을 이룰 수 있다. ${ }^{16)}$

\section{2. 정량적 성과 평가방법}

\subsection{1. 경제적 성과}

기업은 원료와 에너지를 사용하여 제품과 서비스를 생산 하여 판매함으로써, 이윤을 창출하는 것으로 목표로 한다. 이와 같은 생산과정에서 오염물질이 발생하게 되는데, 이를 안전하게 처리하도록 비용을 지출하여야 한다. 따라서 한 기 업체의 제품과 서비스 생산에 따른 경제적 이득은 아래 식으 로 요약하여 나타낼 수 있다.

$$
\pi=\sum_{i=1}^{n} P_{i}-\sum_{i=1}^{n}\left(R_{i}+E_{i}+W_{i}+O_{i}\right)
$$

$$
\begin{array}{ll}
\pi: \text { 경제적 이득 } & \mathrm{P}_{\mathrm{i}} \text { : 상품 } \mathrm{i} \text { 의 가격 } \\
\mathrm{R}_{\mathrm{i}} \text { : 자원비용 } & \mathrm{E}_{\mathrm{i}} \text { : 에너지 비용 } \\
\mathrm{W}_{\mathrm{i}} \text { : 환경관리 비용 } & \mathrm{O}_{\mathrm{i}} \text { : 운영비용 }
\end{array}
$$

그러므로 기업의 이윤은 그 밖의 모든 조건이 동일하다 면 (1) 상품이 더 높은 가격, (2) 에너지 비용감소, (3) 자원비 용감소, (4) 환경관리비용감소 그리고 (5) 운영비용 감소를 통해 증가하게 된다.

생태산업단지 구축사업은 분리되어 있는 기업이 산업공생 을 통해, 사업 전·후의 상품가격을 높이거나, 자원, 에너 지 및 폐기물처리 비용을 절감하게 되어 경제적 성과를 얻 을 수 있다. 즉, 산업공생이 이루어지기 전을 기준 시나리오 (baseline scenario)로 하고 산업공생이 이루어진 후의 산업 공생 시나리오의 제품비용, 자원비용, 에너지 비용, 폐기물 처리비용 및 운영비용의 변화를 이용하여 산정할 수 있다. 산업공생 네트워크 구축사업 후의 이윤에서 산업공생 전 시 나리오(baseline scenario)의 이윤을 감함으로써 시나리오 사 이의 경제적 영향을 아래 식으로 나타낼 수 있다.

$$
\begin{aligned}
\Delta \pi=\pi_{a}-\pi_{b} & =\left(\sum_{i=1}^{n} P_{i, a}-\sum_{i=1}^{n}\left(R_{i, a}+E_{i, a}+W_{i, a}+O_{i, a}\right)\right) \\
& -\left(\sum_{i=1}^{n} P_{i, b}-\sum_{i=1}^{n}\left(R_{i, b}+E_{i, b}+W_{i, b}+O_{i, b}\right)\right)
\end{aligned}
$$

$\mathrm{a}$ : 생태산업단지 구축사업 후 시나리오

b : 생태산업단지 구축사업 전 시나리오(Baseline scenario)

\subsection{2. 환경적 성과}

기업에서 발생하는 환경영향은 크게 수계 배출물, 대기 배출물 그리고 폐기물로 아래식과 같이 나타낼 수 있다.

$E E=\sum_{i=1}^{n}\left(W_{i}+A_{i}+w_{i}\right)$
$\mathrm{EE}$ : 환경적 영향
$\mathrm{W}_{\mathrm{i}}$ : 수계 배출물
$\mathrm{A}_{\mathrm{i}}$ : 대기 배출물
$\mathrm{W}_{\mathrm{i}}$ : 폐기물

생태산업단지 구축사업으로 인하여 산업공생이 이루어지 기 전의 바탕 시나리오와 사업화로 인하여 산업공생이 이 루어진 후의 생태산업단지 구축 시나리오의 수계 배출물, 대 기 배출물, 폐기물 발생량 및 처리량을 비교하여 구축사업 의 환경적 영향을 평가할 수 있다. 산업공생 후의 환경적 영 향에서 산업공생 전(baseline scenario)의 환경적 영향을 감하 면 환경적 영향변화를 아래 식과 같이 나타낼 수 있다.

$$
\begin{aligned}
\triangle E E=E E_{a}-E E_{b} & =\left(\sum_{i=1}^{n} W_{i, a}+\sum_{i=1}^{n} A_{i, a}+\sum_{i=1}^{n} w_{i, a}\right) \\
& -\left(\sum_{i=1}^{n} W_{i, b}+\sum_{i=1}^{n} A_{i, b}+\sum_{i=1}^{n} w_{i, b}\right)
\end{aligned}
$$

a : 생태산업단지 구축사업 후 시나리오

$\mathrm{b}$ : 생태산업단지 구축사업 전 시나리오(베이스라인 시나 리오) 


\section{3. 우리나라 생태산업단지 구축사업}

\section{1. 사업계획}

우리나라 생태산업단지 구축사업은 2005년부터 2019년까 지 3 단계로 추진되며, 산업단지 내 기업 간 또는 주변지역 의 기업과의 연계를 통하여 오염물 무배출을 최종목표로 하 고 있다. 구축사업의 단계별 전략 및 목표는 Fig. 2와 같으 며, 1단계는 생태산업단지 구축 시범사업('05 '09), 2단계는 광역 생태산업단지 구축('10 '14), 3단계는 한국형 생태산업 단지 모델 완성('15 '19)을 목표로 사업이 추진 중이다. ${ }^{19,20)}$

1 단계 사업은 시범사업으로 경북(포항), 전남(여수), 울산 등 3 개의 시범단지를 대상으로 2005년 11 월에 시작되었으

Table 2. Target industrial parks about the $2^{\text {nd }}$ phase development projects of the EIP ${ }^{19,20)}$

\begin{tabular}{|c|c|c|}
\hline \multirow{2}{*}{ Regions } & \multicolumn{2}{|r|}{ Industrial parks } \\
\hline & Hub & Spoke or Sub \\
\hline $\begin{array}{l}\text { Metro- } \\
\text { politan }\end{array}$ & $\begin{array}{l}\text { Ansan, } \\
\text { Siheung }\end{array}$ & $\begin{array}{l}\text { Keom-jun, An-sung1 } \cdot 2 \cdot 3 \text {, Song-tan, Po- } \\
\text { seung }\end{array}$ \\
\hline \multirow[b]{2}{*}{$\begin{array}{l}\text { Chung- } \\
\text { cheong }\end{array}$} & $\begin{array}{l}\text { Asan, } \\
\text { Hyundai steel }\end{array}$ & $\begin{array}{l}\text { Dae-juk, Dae-san, Seo-san, In-ju, Cheon- } \\
\text { an2·3, Tang-jeong }\end{array}$ \\
\hline & $\begin{array}{l}\text { Ochang } \\
\text { hi-tech }\end{array}$ & $\begin{array}{l}\text { High-tech, E-tech, Dae-so, Dae-poong, } \\
\text { Gwang-hye-won, I-wol, Geum-wang, So-i, } \\
\text { Maeng-dong, Jeung-pyeong, Pu-yong, } \\
\text { Osong Bioscience Technopolis, Cheong-ju, } \\
\text { Hyun-do }\end{array}$ \\
\hline \multirow{2}{*}{ Daekyeong } & Sungseo & Dyeing, Seo-dae-gu, Dal-sung $1 \cdot 2$ \\
\hline & Pohang steel & Oe-dong, Gu-mi, Wae-gwan, Da-san1·2 \\
\hline \multirow{2}{*}{ Dongnam } & $\begin{array}{l}\text { Ulsan mipo, } \\
\text { Onsan }\end{array}$ & $\begin{array}{l}\text { Mae-gok, Sin, Gil-cheon1·2, High tech } \\
\text { vally }\end{array}$ \\
\hline & $\begin{array}{l}\text { Myeongji, } \\
\text { Noksan }\end{array}$ & Shin-ho, Sa-sang, Shin-pyeong, Jang-lim \\
\hline \multirow[t]{2}{*}{ Honam } & Gunsan & $\begin{array}{l}\text { Wan-ju, Ik-san1.2, Jeon-ju1.2, Jeong- } \\
\text { eup1 } 2 \cdot 3\end{array}$ \\
\hline & Yeosu & Gwang-yang, O-cheon, Hwa-yang, Dae-bul \\
\hline
\end{tabular}

며, 2006년 3월에 경기(반월·시화) 및 충북(청주)지역을 추 가하여 5 개 지역을 대상으로 본격적인 추진되었다. ${ }^{1921)} 1$ 단계 사업(2005 2009)은 구축사업의 기반구축에 초점을 맞 추어 추진되었으며, 2단계 사업(2010 2014)은 2010년 부산, 대구, 전북 지역이 추가되었고, 2013년도에 충남이 추가되어 총 9 개 지역에서 자원순환네트워크의 확산을 목표로 추진되 고 있다.

2 단계 사업은 5 개의 광역권 사업으로 진행되며(Table 2), 권역별로 2 개의 허브(Hub)단지와 허브단지별로 4 13개의 스포크(Spoke or Sub) 단지를 선정하여 권역 간, 권역 내 단 지 내뿐만 아니라 단지 간으로 산업공생 네트워크를 확대하 여 추진하고 있다. 특히, 1 단계의 성과를 바탕으로 민간의 자 발적 참여 확대를 통한 네트워크 확산에 주력하고 있다. ${ }^{16,20)}$

\section{2. 추진전략}

우리나라 생태산업단지 구축사업은 Fig. 3의 추진조직과 Fig. 4의 과제수행체계에 의해 발굴, 선정, 지원 및 관리되 고 있다. 추진 조직별 주요 업무를 살펴보면, 산업통상자원 부는 제도운영, 기본방향수립, 시범단지 선정 및 재정지원 등의 업무지원을 하고, 사업주관기관인 한국산업단지공단 의 사무국은 기본계획 수립·운영, 세부과제를 확정하고, 지 역EIP사업단 관리 등 총괄 기획조정기능을 맡고 있다. 그리 고 지역EIP사업단은 대상단지별 마스터 플랜 수립, 물질흐 름 분석 및 세부사업 발굴, 지역운영위원회의 구성 - 운영, 지역 $\mathrm{DB}$ 구축 등의 업무를 담당하고 있다. 사무국내 평가 위원회는 생태산업단지의 지정, 물질교환사업 심의, 세부과 제 심의·평가, 지역사업단 평가 및 사후관리심의 등의 업 무를 담당하며, 지역EIP사업단 내 지역운영위원회에서는 과 제 발굴 추천, 포럼활동 지원 및 사업운영 자문 등의 역할 을 수행하고 있다. 이상과 같이 생태산업단지 구축사업은 과 제의 발굴에서 사업화까지 10 단계에 걸쳐 체계적으로 관리 되고 있다.
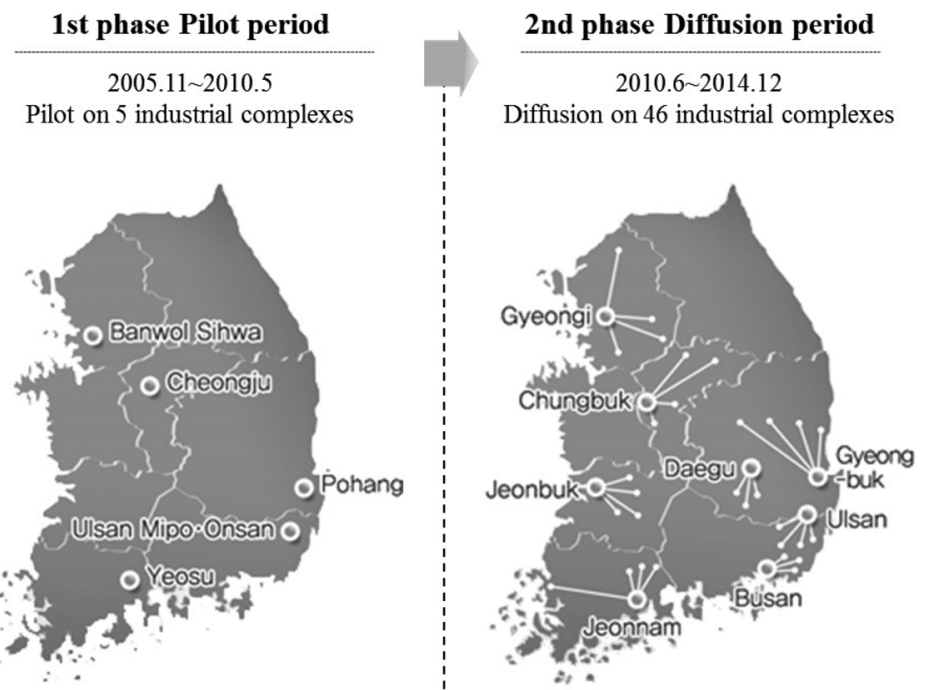

3rd phase Completion period

2015.1 2019.12

Construction of national EIP network

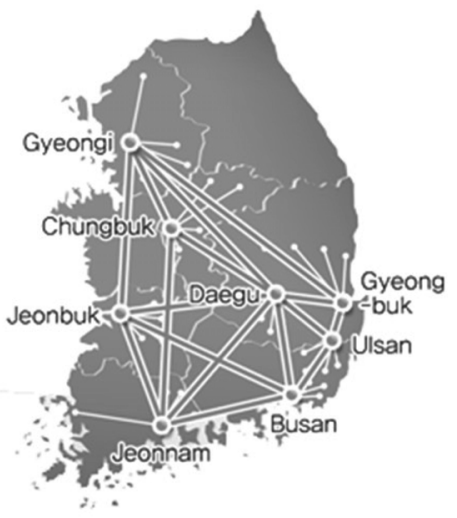

Fig. 2. Staged goals for the development projects of the EIP. ${ }^{24)}$ 


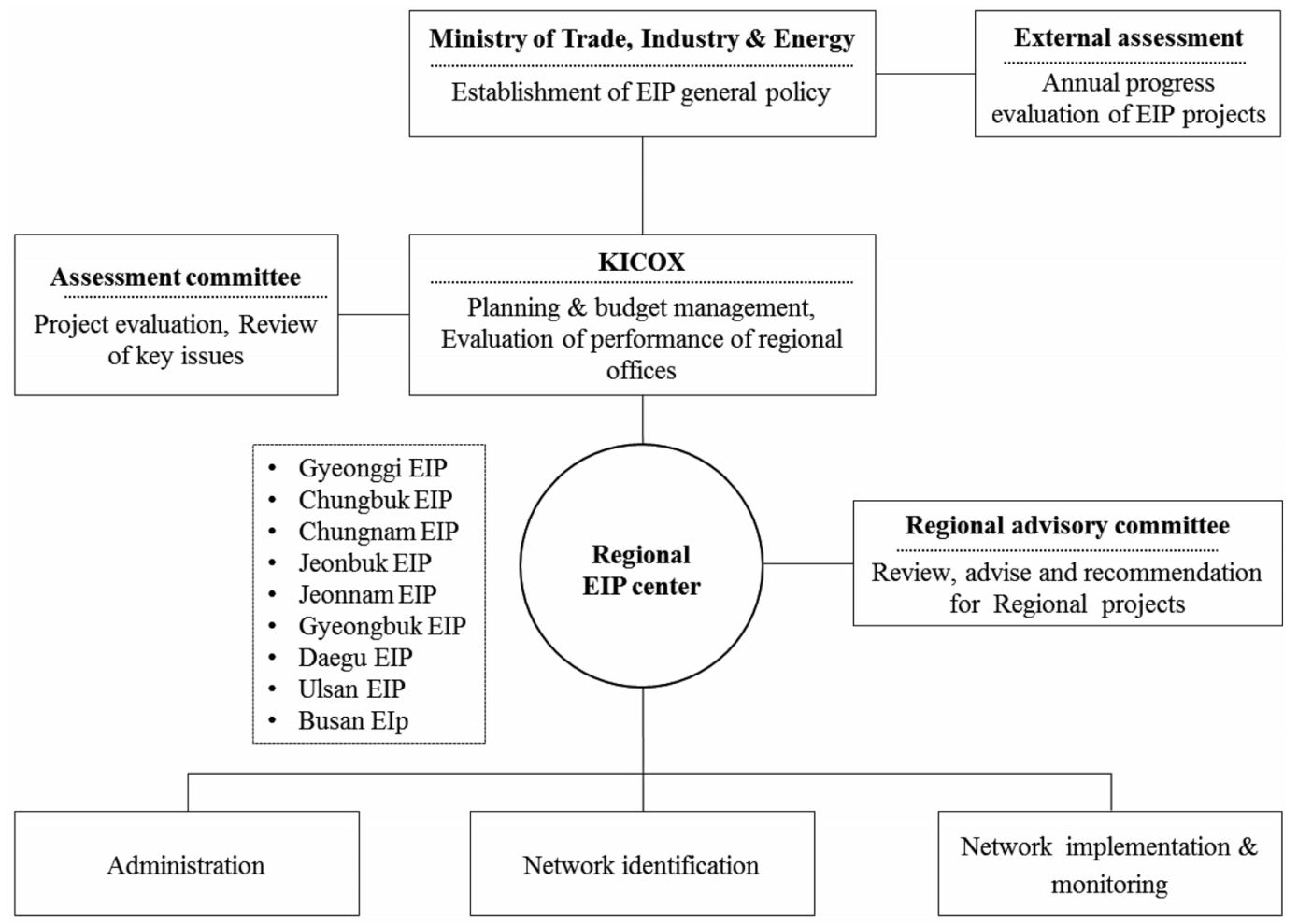

Fig. 3. Organizational structure of EIP initiative. ${ }^{24)}$

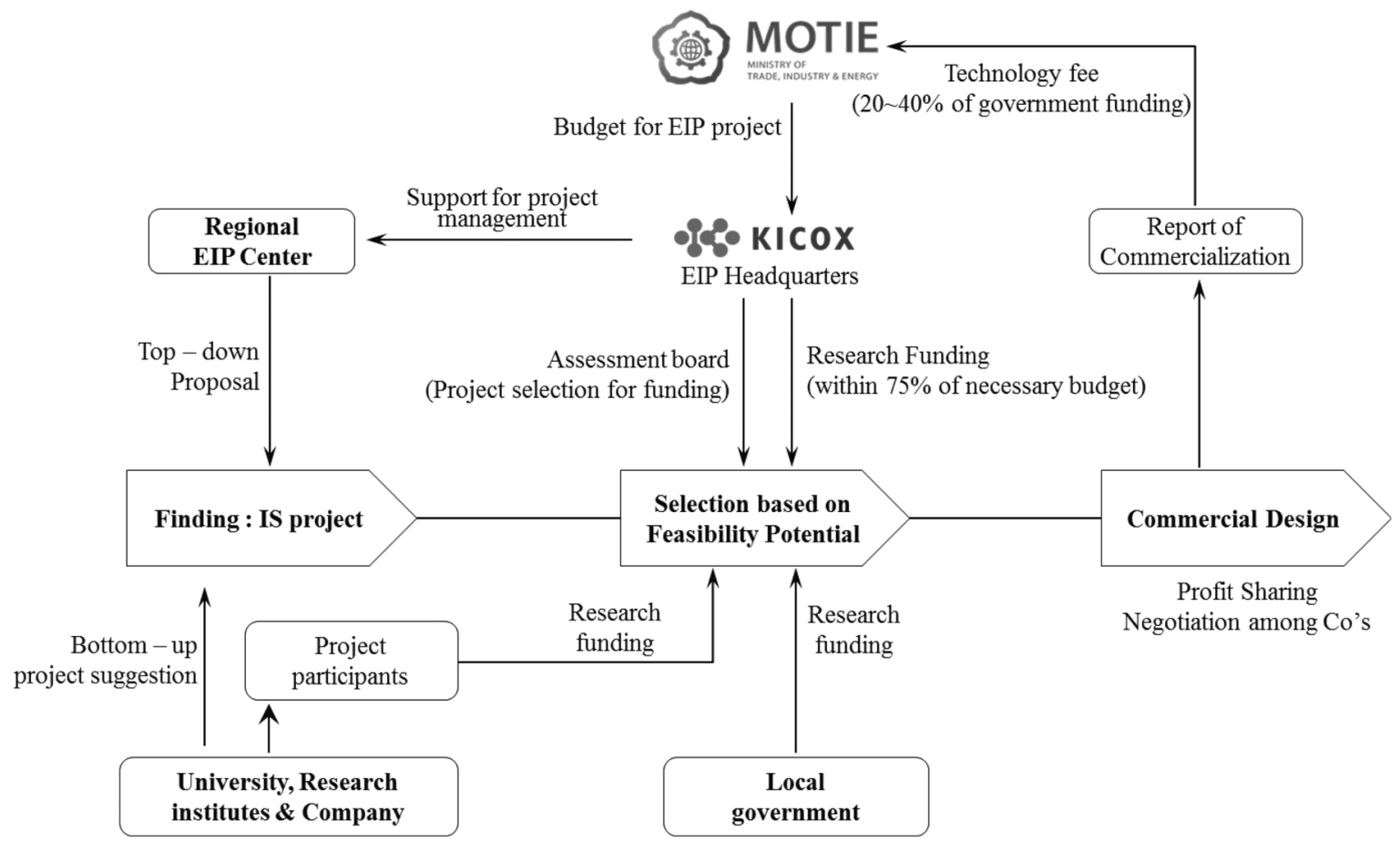

Fig. 4. Implement system of the development projects of the EIP in Korea. ${ }^{24)}$

\section{4. 연구결과 및 고찰}

\section{1. 산업공생 네트워크 발굴 및 사업화}

지역EIP사업단은 생태산업단지 구축사업의 추진기반 조사 를 바탕으로 얻어지는 물질흐름, 자원순환현황, 잠재력 조
사 등의 자료 분석을 통해 도출된 공생 가능한 폐기물/부산 물, 에너지, 용수 및 폐수, 기존의 자생적 자원순환사업 등을 고려하여 생태산업단지 구축사업을 추진하였으며, 지역사업 단별 사업추진 현황은 Table 3과 같다.

Table 3에서와 같이 1단계 1차년도부터 2단계 4차년도까 
Table 3. Status on the development projects of the EIP in Korea

\begin{tabular}{lcccccccccc}
\hline \multicolumn{1}{c}{ Classification } & Sum & Gyeonggi & Ulsan & Busan & Jeonnam & Jeonbuk & Kyeongbuk & Daegu & Chungbuk & Chungnam \\
\hline \hline Founded project & 449 & 52 & 82 & 29 & 97 & 34 & 65 & 39 & 49 & 2 \\
$\quad 1$ stage & 175 & 26 & 52 & - & 48 & - & 28 & - & 21 & - \\
$\quad 2$ stage & 274 & 26 & 30 & 29 & 49 & 34 & 37 & 39 & 28 & 2 \\
Selected project & 296 & 36 & 65 & 20 & 53 & 20 & 48 & 19 & 33 & 2 \\
$\quad 1$ stage & 116 & 15 & 41 & - & 27 & - & 21 & - & 12 & - \\
$\quad 2$ stage & 180 & 21 & 24 & 20 & 26 & 20 & 27 & 19 & 21 & 2 \\
Selection rate & $66 \%$ & $69 \%$ & $79 \%$ & $69 \%$ & $55 \%$ & $59 \%$ & $74 \%$ & $49 \%$ & $67 \%$ & $100 \%$ \\
Ended project & 244 & 28 & 56 & 15 & 48 & 14 & 40 & 14 & 29 & 0 \\
Processing project & 52 & 8 & 9 & 5 & 5 & 6 & 8 & 5 & 4 & 2 \\
Commercialized project & 118 & 11 & 27 & 8 & 25 & 9 & 19 & 8 & 11 & 0 \\
Commercialization rate & $48 \%$ & $39 \%$ & $48 \%$ & $53 \%$ & $52 \%$ & $64 \%$ & $48 \%$ & $57 \%$ & $38 \%$ & - \\
\hline
\end{tabular}

지 9년간 생태산업단지 구축사업을 위해 449 개의 세부과제 를 발굴하였으며, 이 중 전남사업단이 97 개로 가장 많은 과 제를 발굴하였고 울산사업단이 82 개를 발굴하여 뒤를 이었 다. 발굴된 세부과제 중 296 개가 연구사업 수행과제로 선정 되어, 과제 선정률이 약 $66 \%$ 로 나타났다. 지역별로 살펴보 면, 선정된 과제 수는 울산사업단에서 65 개로 가장 많았고 전남사업단이 53 개로 그 뒤를 이었으며, 과제 선정률은 울 산사업단이 약 $79 \%$, 경북사업단도 약 $74 \%$ (선정/발굴: $48 / 65$ ) 로 높게 나타났다. 충남사업단은 2013년도에 설립되어 짧은 사업 참여에도 불구하고 2 개 사업을 발굴하여 2 개 사업이 선정되었다.

한편, 연구가 진행된 296 개의 과제 중 244 개는 이미 연구 수행이 완료되었고 52 개는 현재 진행 중에 있다. 완료된 과 제 244 개 중 118 개는 사업화되어 8 개 지역사업단의 평균 사 업화 성공률은 약 $48 \%$ 로 나타났다.

사업화성과는 사업이 시작된 2005년에서 2년이 경과한 2007년부터 발생되었으며, 이후 매년 증가하였다. 이러한 부분은 과제가 종료된 이후 즉각적으로 사업화가 진행되는 경우보다 일정기간 사업화를 위한 시간이 소요되는 것을 의 미한다. Pilot 형태의 과제에서 실용화를 위한 준비기간이 나, 열 공급을 위한 배관 및 설비 공사, 인허가의 문제, 제 품 단가 협상기간 등의 사업화가 준비되는데 있어 시간적 인 여유가 필요한 것으로 나타났다. 즉, 생태산업단지 구축 사업은 과제가 진행되는 기간 외 사업화를 위한 준비기간 이 필요하며, 준비기간 동안 지역사업단은 과제 진행기관에 대한 충분한 관리가 필요함을 알 수 있다.

8 개 지역 사업단 중 울산사업단에서 27 개의 과제가 사업 화되어 가장 많았으며, 전남사업단이 25 개로 뒤를 이었다. 사업화가 가장 많이 이루어진 울산사업단의 경우 완료된 과 제가 56 개로 타 사업단 보다 많아 사업화 성공률은 $48 \%$ 이 었으나, 전북, 대구, 부산, 전남 사업단의 성공률은 각각 64 $\%$ (사업화/종료: 9/14), 57\% (8/14), 53\% (8/15), 52\% (25/48) 로 울산보다 높게 나타났다.

울산지역에서 세부과제가 많이 발굴된 것은 울산 산업단 지에 자동차, 조선, 석유화학 및 비철금속 등 다양한 업종
이 입주하고 있어, 이들 업체에서 배출되는 부산물, 폐기 물, 폐수 및 잉여 에너지를 다른 기업체의 원료나 연료로 사 용하는 산업공생 생태계를 구축하기에 유리한 여건으로 이 루어져 있기 때문이다. 그리고 사업화된 과제 수가 타 지역 에 비하여 울산사업단이 많은 것도 산업단지의 환경개선을 위한 울산시의 정책의지와 산업단지 입주기업들의 환경개 선 노력과 높은 참여, 그리고 사업단의 체계적인 사업 발굴 노력에 따른 결과로 판단된다.

생태산업단지 구축사업과제를 유형별로 정리하면 Table 5 와 같다. 현재까지 진행된 296개의 과제 중 폐기물/부산물

Tabel 4. Status on the commercialized projects of the EIP in Korea

\begin{tabular}{|c|c|c|c|c|c|c|c|c|c|}
\hline Classification & 2005 & 2006 & 2007 & 2008 & 2009 & 2010 & 2011 & 2012 & 2013 \\
\hline $\begin{array}{l}\text { Commercial- } \\
\text { ized project }\end{array}$ & - & - & 1 & 2 & 10 & 17 & 20 & 33 & 35 \\
\hline $\begin{array}{c}\text { Waste/ } \\
\text { by-product }\end{array}$ & - & - & - & 1 & 7 & 11 & 15 & 24 & 24 \\
\hline Energy & - & - & 1 & 1 & 1 & 6 & 5 & 9 & 10 \\
\hline $\begin{array}{c}\text { Water/ } \\
\text { waste water }\end{array}$ & - & - & - & - & - & - & - & - & - \\
\hline Others & - & - & - & - & - & - & - & - & - \\
\hline
\end{tabular}

Table 5. Type of the development projects of the EIP in Korea

\begin{tabular}{cccccc}
\hline \multirow{2}{*}{ Region } & \multicolumn{5}{c}{ Project area } \\
\cline { 2 - 6 } & $\begin{array}{c}\text { Waste/ } \\
\text { by-product }\end{array}$ & Energy & $\begin{array}{c}\text { Water/ } \\
\text { waste water }\end{array}$ & Others & Sum \\
\hline \hline Gyeonggi & 18 & 13 & 2 & 3 & 36 \\
Ulsan & 37 & 21 & 3 & 4 & 65 \\
Busan & 11 & 9 & - & - & 20 \\
Jeonnam & 42 & 5 & 2 & 4 & 53 \\
Jeonbuk & 16 & 3 & 1 & - & 20 \\
Kyeongbuk & 33 & 9 & 2 & 4 & 48 \\
Daegu & 15 & 3 & 1 & - & 19 \\
Chungbuk & 13 & 13 & 3 & 4 & 33 \\
Chungnam & 2 & - & - & - & 2 \\
\hline Total & 187 & 76 & 14 & 19 & 296 \\
\hline
\end{tabular}


분야가 187 개로 진행된 과제의 약 $63 \%$ 를 나타낸다. 전남사 업단이 42 개로 8 개 사업단 중 폐기물/부산물 분야로 가장 많은 과제가 수행되었으며, 울산사업단과 경북사업단이 각 각 37 개, 33 개로 뒤를 이었다. 특히 전남사업단은 53 개의 세부과제 중 42 개의 과제가 폐기물/부산물 분야로 진행되 어 선정된 과제 중 약 $79 \%$ 가 폐기물/부산물 분야로 수행되 었다. 그리고 에너지와 용수 및 폐수분야가 각각 76 개, 14 개로 나타나 유틸리티사업이 90 개로 약 $30 \%$ 를 차지하는 것 으로 나타났으며, 울산사업단에서 24 개의 과제(에너지 분야: 21 개, 용수 및 폐수분야: 3 개)가 유틸리티사업으로 수행되어 8 개 사업단 중 가장 많았다. 전체적으로 세부과제는 폐기물 및 부산물 재이용 분야가 많이 진행되었는데, 이는 에너지나 용수 및 폐수보다 활용가능한 부산물의 종류가 다양하고 중 소형기업에서의 기술개발이 유리하였기 때문으로 판단된다.

생태산업단지 구축사업을 수행한 주관기관 현황을 살펴 보면, 선정된 과제의 약 $79 \%$ 인 234 개의 세부과제가 기업체 에 의해 수행되어 가장 높게 나타났으며, 대학(34개, $11 \%)$, 연구기관(21개, $7 \%$ ), 유관기관(6개, $2 \%$ ) 순으로 나타났다. 경북사업단과 전남사업단에서 41 개의 세부과제가 기업체 에 의하여 수행되어 가장 많았으며, 특히 경북사업단의 경 우 48 개의 세부과제 중 41 개의 과제가 기업체에 의하여 수 행되어 선정된 과제 중 약 $85 \%$ 가 기업체에 의하여 수행되 었다. 그리고 대학에 의하여 수행된 세부과제는 대부분 울산 사업단과 전남사업단에서 수행되어진 것으로 나타났으며, 이 때 울산사업단과 전남사업단에서 각각 17 개와 10 개가 대 학에 의해 수행되었다.

이는 사업의 초기에는 산업공생 네트워크 사업을 기술개 발 사업으로 인식하고 대학교가 주관을 많이 하였으나, 생 태산업단지 구축사업은 기 개발된 기술을 현장에 접목하는 적용 연구를 통한 사업화로 인식이 정착되면서, 기업이 사 업을 주관하고, 대학교 및 연구기관은 참여기관으로서 애 로사항을 해결해주는 방향으로 세부과제가 진행방식이 변 화되었기 때문이다. 그러나 이해당사자가 많은 경우, 이를 조정해 주는 역할로, 대학교가 주관연구기관으로 참여하고,

Table 6. Managing institutes of the development projects of the EIP in Korea

\begin{tabular}{cccccc}
\hline \multirow{2}{*}{ Region } & \multicolumn{5}{c}{ Status of managing institutes } \\
\cline { 2 - 6 } & $\begin{array}{c}\text { Private } \\
\text { organization }\end{array}$ & $\begin{array}{c}\text { Govern- } \\
\text { ment }\end{array}$ & $\begin{array}{c}\text { Research } \\
\text { institute }\end{array}$ & Company & University \\
\hline \hline Gyeonggi & 0 & 1 & 4 & 25 & 6 \\
Ulsan & 0 & 1 & 7 & 40 & 17 \\
Busan & 0 & 2 & 0 & 18 & 0 \\
Jeonnam & 0 & 1 & 1 & 41 & 10 \\
Jeonbuk & 0 & 0 & 0 & 20 & 0 \\
Kyeongbuk & 0 & 0 & 7 & 41 & 0 \\
Daegu & 0 & 1 & 1 & 17 & 0 \\
Chungbuk & 1 & 0 & 1 & 30 & 1 \\
Chungnam & 0 & 0 & 0 & 2 & 0 \\
\hline Total & 1 & 6 & 21 & 234 & 34 \\
\hline
\end{tabular}

다수의 기업들이 참여기업으로 컨소시엄을 구성함으로써, 효율적인 성과를 내는 경우도 있어, 산업공생 네트워크는 사업화를 효과적으로 할 수 있도록 연구팀을 어떻게 구성하 느냐가 사업화에 큰 영향을 미침을 확인할 수 있었다.

\section{2. 생태산업단지 구축사업의 성과}

\subsection{1. 경제적 성과}

생태산업단지 구축사업의 경제적 분야는 식 (2)를 이용하 여 산출하였다. 폐기물 및 부산물 분야의 세부과제의 경우 폐기물 및 부산물 처리비용 절감효과는 생태산업단지 구축 사업 전의 처리비용에서 사업 후의 처리비용을 차감하여 산 정하였으며, 원료비용 절감효과는 기존원료물질의 구입비 용에서 재활용되는 물질을 구입하는 비용을 차감하여 산정 하였다. 그리고 중간 처리하여 폐기물 및 부산물을 제품화 하여 판매함으로써 발생하는 신규매출 효과는 재활용된 제 품의 가격과 수량을 활용하여 산정하였다. 에너지 및 유틸 리티 과제의 경우 에너지의 판매로 인한 신규매출 및 에너 지 공급으로 인한 사업 전/후의 연료사용비용 차익을 비용 절감으로 산정하였다. 폐수 및 용수의 경우 폐기물 및 부산 물의 경제적 효과 산정과 유사하게 처리비용에 대한 절감 을 비용절감으로 산정하고, 용수 및 폐수로 인한 원료 회수 또는 이용을 제품화하여 판매함으로써 발생하는 부분을 신 규매출로 산정하였다.

사업단별 사업화된 생태산업단지 구축사업의 세부과제에 대해 전술한 평가방법으로 산정한 경제적 효과를 Table 7에 나타내었으며, 118 개의 사업화된 과제에 153 억 원의 정부연 구비가 투입되어 비용절감(약 1,298.2억 원/년)과 신규매출

Table 7. An economic achievements project type and of various EIP division on the development projects of the EIP in Korea

\begin{tabular}{|c|c|c|c|c|c|c|}
\hline \multirow{2}{*}{\multicolumn{2}{|c|}{ Classification }} & \multirow{2}{*}{$\begin{array}{l}\text { Rese- } \\
\text { arch } \\
\text { fund }\end{array}$} & \multicolumn{3}{|c|}{$\begin{array}{c}\text { Economic benefit } \\
\text { (hundred million KRW/year) }\end{array}$} & \multirow{2}{*}{$\begin{array}{l}\text { Investment } \\
\text { (hundred } \\
\text { million } \\
\text { KRW) }\end{array}$} \\
\hline & & & $\begin{array}{c}\text { Cost } \\
\text { reduction }\end{array}$ & $\begin{array}{l}\text { New } \\
\text { sales }\end{array}$ & Sum & \\
\hline \multirow{3}{*}{ Type } & $\begin{array}{l}\text { Waste/by- } \\
\text { product }\end{array}$ & 109 & 516 & 1,184 & 1,700 & 997 \\
\hline & Energy & 41 & 727 & 624 & 1,351 & 2,767 \\
\hline & $\begin{array}{c}\text { Water/waste } \\
\text { water }\end{array}$ & 3 & 55 & 5 & 60 & 6 \\
\hline \multirow{10}{*}{$\begin{array}{l}\text { Re- } \\
\text { gion }\end{array}$} & Gyeonggi & 20 & 137.0 & 122.4 & 259.4 & 1,238 \\
\hline & Ulsan & 32 & 659.3 & 420.5 & $1,079.8$ & 1,154 \\
\hline & Busan & 8 & 55.9 & 78.6 & 134.5 & 62 \\
\hline & Jeonnam & 40 & 212.5 & 596.6 & 809.1 & 614 \\
\hline & Jeonbuk & 10 & 50.3 & 57.4 & 107.7 & 79 \\
\hline & Kyeongbuk & 23 & 139.4 & 330.4 & 469.8 & 467 \\
\hline & Daegu & 9 & 16.9 & 112.4 & 129.3 & 70 \\
\hline & Chungbuk & 11 & 26.8 & 94.7 & 121.5 & 85 \\
\hline & Chungnam & - & - & - & - & - \\
\hline & Total & 153 & $1,298.2$ & $1,813.0$ & $3,111.1$ & 3,770 \\
\hline
\end{tabular}


(약 $1,813.0$ 억 원/년)에 의해 약 $3,111.1$ 억 원/년의 경제적 효 과와 3,770억 원의 투자효과를 유발하였다.

정부연구비 1 억당 경제적 효과는 20.3 억 원으로 높은 수 준으로, 부산물 15.6 억 원, 에너지 33.0 억 원, 용수 및 폐수 20.0 억 원으로 에너지 과제에 의한 효과가 가장 높은 것으 로 나타났다.

전체 사업화 된 118 개의 과제 중 폐기물/부산물 과제가 1,700 억 원/년으로 가장 높은 경제적 효과를 나타내었으며, 에 너지 과제가 1,351 억 원/년, 용수 및 폐수가 60 억 원/년으로 부산물과 에너지 과제에 의한 경제적 효과가 높은 것으로 나 타났다. 과제 건으로 비교하면, 에너지과제가 1 건당 40.9 억 원/년의 효과를 나타내었으며, 폐기물 및 부산물 20.7억 원/ 년, 용수 및 폐수 19.9억 원의 효과를 나타내 에너지과제에 의한 경제적 효과가 가장 높은 것으로 나타났다. 에너지과 제의 경우 경제적 효과의 기준이 될 수 있는 에너지 원단위 가 다른 유형의 과제보다 높은 수준으로 형성되고 있고, 이러 한 부분은 매출 및 비용절감부분에 큰 기여를 할 수 있다.

경제적 효과는 27 건의 사업화 성과 중 13 건이 에너지 과 제인 울산사업단이 가장 높았으며, 비용절감(659.3억 원/년) 및 신규매출(420.5억 원/년)에 의해 약 $1,079.8$ 억 원/년의 경 제적 효과를 얻었다. 이는 9 개 지역사업단에서 사업화를 통 하여 얻은 경제적 효과에 약 $34.7 \%$ 를 차지하는 수치이다. 사업화 성과가 25 개로 비슷한 전남사업단의 경우 809 억 원 의 경제적 효과로 울산사업단 다음으로 높은 경제적 효과 를 나타내었다. 전남사업단의 경우 부산물 과제의 사업화성 과가 21 건으로 전체 사업화 성과의 25 건 중 $84 \%$ 이며 이를 통한 경제적 성과는 764 억 원/년으로 $94 \%$ 수준으로 나타났 다. 울산사업단의 에너지 성과는 건당 62.1 억 원/년의 성과 를 나타내 전체 40 억 원의 수준보다 높았으며, 전남사업단 의 경우 폐기물 및 부산물 과제가 건당 36.5 억 원/년 전체 20 억 원의 수준보다 높은 것으로 확인되었다.

투자비의 경우 사업화 건수가 11 건으로 울산과 전남, 경 북보다 사업화 건수가 적은 경기사업단이 1,238 억 원의 투 자효과가 발생되어 가장 높은 투자효과가 나타났으며, 이 중 에너지 과제 5 건에 의한 1,223 억 원이 대부분을 차지하 였다. 울산사업단의 경우 경기사업단 다음으로 투자효과가 높은 1,154 억 원으로 높았으며, 에너지 과제 13 건에 의한 투자비가 1,101 억 원으로 경기사업단과 마찬가지로 에너지 과제에 의한 투자효과가 대부분으로 나타났다. 118 건의 사 업화를 통한 총 투자비 3,770 억 중 에너지에 의한 투자비 가 2,767 억 원으로 $73 \%$ 를 차지하였으며, 폐기물 및 부산물 과제는 997 억 원으로 $26.4 \%$ 수준으로 나타났다. 부산물의 사업화 성과가 82 건으로 많은 것에 비해 에너지 과제의 사 업화 성과는 33건으로 사업화 건수는 적으나 투자효과는 더 욱 많이 발생되는 것으로 나타났다. 부산물에 비해 에너지 의 투자비가 많은 이유로는 에너지 사업화의 경우 열원 이 송을 위한 배관 설비 및 공사비, 기타 유틸리티 시설이 필 요하나, 부산물의 경우 기존 설비의 활용 또는 낮은 설비투 자비로 인한 차이로 판단된다.
Table 8. An environmental achievements of project type and various EIP division on the development projects of the EIP in Korea

\begin{tabular}{|c|c|c|c|c|c|}
\hline \multicolumn{2}{|c|}{ Classification } & \multicolumn{4}{|c|}{$\begin{array}{c}\text { Environmental benefit } \\
\text { (ton/year, toe/year, } \mathrm{tCO}_{2} / \text { year) }\end{array}$} \\
\hline & & Waste & Water & Energy & GHGs \\
\hline \multirow{3}{*}{ Type } & $\begin{array}{c}\text { Waste/ } \\
\text { by-product }\end{array}$ & 802,653 & 22,405 & 12,120 & 487,122 \\
\hline & Energy & 25,280 & 120,480 & 238,355 & 620,067 \\
\hline & $\begin{array}{c}\text { Water/ } \\
\text { waste water }\end{array}$ & 180 & 72,632 & - & - \\
\hline \multirow{10}{*}{$\begin{array}{l}\text { Re- } \\
\text { gion }\end{array}$} & Gyeonggi & $46,404.0$ & $88,000.0$ & $11,192.0$ & $45,281.0$ \\
\hline & Ulsan & $234,060.6$ & 470.0 & $23,126.0$ & $113,912.0$ \\
\hline & Busan & $11,735.0$ & 200.0 & 0.0 & $12,800.0$ \\
\hline & Jeonnam & $14,860.0$ & 0.0 & $20,198.0$ & $51,719.0$ \\
\hline & Jeonbuk & $37,024.0$ & $79,007.0$ & $187,260.5$ & $450,969.7$ \\
\hline & Kyeongbuk & $345,753.0$ & $10,980.0$ & 0.0 & $316,189.4$ \\
\hline & Daegu & $117,117.0$ & 0.0 & 0.0 & $91,800.0$ \\
\hline & Chungbuk & $21,159.0$ & $36,860,0$ & $8,698.0$ & $24,518.0$ \\
\hline & Chungnam & - & - & - & - \\
\hline & Total & $828,112.6$ & $215,517.0$ & $250,474.5$ & $1,107,189.1$ \\
\hline
\end{tabular}

\subsection{2. 환경적 성과}

사업단별 사업화된 생태산업단지 구축사업의 세부과제에 대한 환경적 효과는 식 (3)에 의하여 산출하여 Table 8에 나 타내었는데, 118 개의 사업화된 과제를 통하여 폐기물 및 부산물 828,113톤/년, 용수 및 폐수 215,517톤/년, 에너지 250,475 toe/년, 온실가스 $1,107,189 \mathrm{tCO}_{2}$ 년을 절감하였다. 폐기물/부산물 유형의 과제의 경우 부산물 저감효과가 802,653 톤/년으로 전체 저감량의 $97 \%$ 를 구성하여 폐기물/ 부산물 저감에 가장 큰 효과를 나타내었으며, 폐기물/부산물 저감 외에도 용수 및 폐수, 에너지, 온실가스 부분에가 각각 저감효과를 발생하였다. 특히, 온실가스의 경우 $487,122 \mathrm{tCO}_{2} /$ 년으로 전체 저감량의 $44 \%$ 수준으로 높았으며, 이는 폐기물/ 부산물의 소각 또는 기타 처리시 발생되는 $\mathrm{CO}_{2}$ 를 저감하는 효과이다. 에너지 과제의 경우 에너지 저감량이 238,355 toe/ 년으로 전체 저감량의 $95 \%$ 수준으로 대부분을 차지하였으 며, 온실가스 역시 $56 \%$ 수준으로 나타났다. 에너지 과제 역 시 부산물/폐기물 저감 및 용수 및 폐수 저감에도 효과를 나 타내어 생태산업단지 구축사업을 통해 발생되는 사업화 성 과는 과제의 유형에 집중적인 효과 외에도 그 외의 환경적 효과를 동반하여 나타나는 것으로 확인되었다.

이러한 부분은 각 지역사업단에서 이루어진 사업화 성과의 유형에 따라 효과가 높게 나타날 수 있다. 폐기물/부산물 과 제의 사업화 성과가 높은 전남사업단은 폐기물/부산물 저감 의 효과가 높게 나타나고, 에너지 과제의 사업화 성과가 높 은 울산사업단은 에너지와 온실가스 저감이 높게 나타났다. 지역별로 살펴보면 폐기물/부산물은 $345,753.0$ 톤/년으로 전 남사업단이 가장 높았으며, 용수 및 폐수는 88,000.0톤/년으 로 경기사업단이, 에너지와 온실가스는 각각 $187,260.5$ toe/년, $450,969.7 \mathrm{tCO}_{2}$ /년으로 울산사업단이 가장 높게 나타났다. 
Table 7의 연구비를 기준으로 하면 정부연구비 1 억당 폐기 물/부산물 5,408톤, 용수 및 폐수 1,407톤, 에너지 1,635 toe, 온실가스 7,231 $\mathrm{tCO}_{2}$ 의 저감효과를 나타내어, 낮은 정부연 구비 투입으로 높은 효과를 볼 수 있는 것으로 확인되었다.

\section{3. 생태산업단지 구축사업의 활성화를 위한 정책 제안}

우리나라의 생태산업단지 구축사업은 산업단지 환경문제 를 완화시키고, 기업체의 자원 및 에너지 효율성을 제고하 기 위한 산업공생네트워크를 구축하여 기존 산업단지를 생 태산업단지로 전환시키는 것을 목적으로 하고 있다. 산업 통상부는 사업을 추진하면서 '환경친화적 산업구조로의 전 환촉진에 관한 법률'을 개정하고, 장기적인 국가연구사업(3 단계 15 년)으로 체계적인 준비와 법적인 뒷받침을 하였다. 특히, 한국산업단지관리공단을 주관기관으로 하여 Fig. 4와 같이 일반 국가 R\&D (research and development) 프로젝트 를 산업공생 네트워크를 발굴하여 적용 연구를 통해 산업공 생네트워크가 사업화가 되도록 R\&BD (research and business development)사업으로 관리되고 있다.

하지만, 이 사업은 환경부와 밀접한 관계에 있어 '환경친 화적 산업구조로의 전환촉진에 관한 법률'에 생태산업단지 의 지정은 산업통상자원부가 환경부와 협의하도록 되어있 고, 산업단지 개발계획 수립시 산업단지지정권자인 국토해 양부와 생태산업단지 관련 협의하도록 ${ }^{3)}$ 명시되어 있음에 도 유기적인 협조가 부족한 실정이다. 또한, 생태산업단지 구축사업의 추진을 위해 필요한 환경 및 에너지 관련 자료 는 중앙행정기관 및 지방자치단체로부터 '공공기관 운영에 관한 법률'에 따라 공공기관의 필요한 자료를 요청 ${ }^{22}$ 하여 제공 받을 수 있지만, 실질적인 협조와 협력이 원활하지 못 한 것이 현실이다.

한편, 부산물/폐기물 교환 및 재이용에 대한 '폐기물관리 법, '자원의 절약과 재활용 촉진에 관한법률' 과의 법적 상 충으로 인해 폐기물을 자원사업이 지연되거나, 이루어지지 않는 경우가 발생하고 있다. 또한 에너지기본법, 에너지이 용합리화법 그리고 대기오염방지법의 상충에 의해서도 에 너지 분야 네트워크 사업이 제한을 받고 있어, 법 및 제도 적 개선과 부처 간의 원활한 협조체계의 구축이 매우 필요 하다. 생태산업단지 구축사업이 원활히 추진되기 위해서는 산업단지 지정, 건설 및 관리, 환경 및 에너지 관리와 관계 되는 부처 간의 유기적 협조를 위한 법 및 제도의 정비가 필요하다.

또한, 현재의 사업은 투자회수기간이 대체로 3 년 이내의 수익성이 좋은 사업 위주로 추진되고 있으나, 회수기간이 10 년 내외가 소요되는 생태산업단지 구축사업은 제도적, 기 술적인 문제가 없음에도 불구하고, 재정적인 이유로 사업이 추진되지 못하고 있다. 또한 투자회수 기간이 짧더라도 초 기투자비가 큰 경우도 사업 추진에 어려움이 있는 것으로 나타났다. 1단계 생태산업단지 구축사업에서 추진된 116 개 과제 중 투자비문제로 사업화가 지연된 과제는 10 개로 1,440 억 원 투자시 발생될 수 있는 이익인 기회비용은 841 억 원/
년이지만, ${ }^{23)}$ 이러한 투자비용은 중소형기업에서 투자하기 에는 무리가 있는 비용이다. 이와 같은 투자비용 문제를 해 소하기 위하여 정부 또는 지자체의 저금리 자금의 융자 지 원이나, 대형 투자가 필요한 사업은 PPP (public private partnership) 사업으로 추진하는 생태산업단지 구축사업 투자지 원정책이 필요하다.

한편, 생태산업단지 구축사업은 기업 간 산업공생 네트워 킹 사업 중심으로 추진되어, 산업단지 환경문제 해결과 경 쟁력 제고에 기여하고 있으나, 산업과 도시의 공생을 통한 지역의 환경문제와 도시경쟁력 제고에도 기여할 수 있도록 사업이 확대되는 것도 필요하다. 이를 위해 산업단지와 도 시의 물, 대기, 폐기물, 에너지 관리와 같이 분절된 접근에 서 통합적 접근을 통한 지속가능한 지역발전의 기반으로서 생태산업단지 구축사업이 추진되도록 하는 정책적 배려가 필요하다.

\section{4. 결 론}

본 연구에서는 2005년부터 2013년까지 국내에서 진행된 생태산업단지 구축사업 중 사업화된 구축사업의 경제적 및 환경적 성과를 평가하고, 구축사업이 산업단지의 변화에 미 친 영향을 살펴보고자 하였다. 이를 위해 국내에서 이루어 진 구축사업 중 사업화된 118 건을 대상으로 정량적 성과를 평가하여 다음과 같은 결론을 얻었다.

국내의 생태산업단지 구축사업은 2005년부터 2013년까 지 449개의 아이템을 발굴하여 296개가 수행되었으며, 이 중 244 개의 과제가 완료되었고 52 개의 과제는 현재 수행 중 에 있다. 완료된 과제 중 118 개의 과제가 사업화되어 사업 화 성공률이 약 $48 \%$ 로 나타났다.

118 개의 사업화된 과제에 153 억 원의 정부연구비가 투입 되어 3,111.1억 원/년의 경제적 효과와 3,770 억 원의 투자효 과를 유발하였고, 폐기물 및 부산물 828,113 톤/년, 용수 및 폐 수 215,517 톤/년, 에너지 250,475 toe/년, 온실가스 $1,107,189$ $\mathrm{tCO}_{2}$ /년을 절감하는 환경적 효과를 달성하였다. 또한, 514 개의 일자리를 창출하여 사회적인 부분도 기여를 하여, 우 리나라의 생태산업단지 구축사업은 국내외적으로 성공적인 사업으로 자리매김 되고 있다.

하지만, 아직도 생태산업단지에 관계된 관계 부처 간 유기 적 협조와 협력의 부족 및 법 및 제도적 한계로 인한 부산 물/폐기물 또는 에너지의 산업공생 추진에 어려움이 있어, 관계 부처 간 통합적 정비 및 전략수립이 필요하다. 또한, 생 태산업단지구축사업 추진에 필요한 자금 해소를 위한 정부 의 저금리 융자 지원 또는 PPP 사업의 투자정책도 요구된다.

한국의 생태산업단지 구축사업이 지속가능한 산업단지모 델로 전국적으로 확대되기 위해서 전문 인력 양성, 지자체 의 참여 및 지원 제고, 기업체의 자발적 참여를 제고, 예산 확대 및 제도 개선을 위한 범부처적, 학제적 협력이 필요한 것으로 판단된다. 


\section{Acknowledgement}

본 연구는 산업통상자원부와 한국산업단지공단의 생태산 업단지구축사업의 일환으로 수행되었으며, 이에 감사드립 니다.

KSEE

\section{References}

1. Kim, J. W., Shishir, K. B. and Park, H.-S., "Clean technology session : Strategies and prospects for Ulsan Eco-Industrial Park project," Kor. Soc. Environ. Eng. Conference Proc., pp. 567 571(2008).

2. Ehrenfeld, J. and Gertler, N., "Industrial ecology in practice: The evolution of interdependence at kalundborg," J. Ind. Ecol., 1(1), 67 79(1997).

3. Ministry of Trade, Industry and Energy, "Act on the promotion of the conversion into environment-friendly industrial structure," Act No. 12154, Jan.1(2014).

4. Ministry of Environment, "Construction of eco-industrial park for sustainable development," GOVP1200211318(2002).

5. Park, H.-S., Eco-efficient and sustainable urban infrastructure development in asia and latin america, ECLAC, UNESCAP (2009).

6. Massard, G., Jacquat, O. and Zürcher, D., Innovation Section, International survey on eco-innovation parks, Federal Office for the Environmental (FOEN); ERA-NET; ECO-INNOVERA, p. 310(2014).

7. Liu, J. 1. M., "Study on comparison of eco-industrial parks in japan, china and korea," J. Global Environ. Eng., 13, 21 (2008).

8. Behera, S. K., Kim, J., Lee, S., Suh, S. and Park, H., "Evolution of 'designed' industrial symbiosis networks in the ulsan eco-industrial park: 'research and development into business' as the enabling framework," J. Clean. Prod. Conference Proc., pp. 103 112(2012).

9. Boix, M., Montastruc, L., Azzaro-Pantel, C. and Domenech S., "Optimization methods applied to the design of ecoindustrial parks: A literature review," J. Clean. Prod., 87(15), 303 317(2015).

10. Chae, S. H., Kim, S. H., Yoon, S. and Park, S., "Optimization of a waste heat utilization network in an eco-industrial park," Appl. Energy, 87(6), 1978 1988(2010).

11. Park, H. and Behera, S. K., "Methodological aspects of applying eco-efficiency indicators to $\hat{A}$ industrial symbiosis net works," J. Clean. Prod., 64, 478 485(2014).

12. Park, H., Rene, E. R., Choi, S. and Chiu, A. S. F., "Strategies for sustainable development of industrial park in ulsan, south Korea - From spontaneous evolution to systematic expansion of industrial symbiosis," J. Environ. Manage., 87(1), 1 13(2008).

13. Yoo, C. K., Heo, S. K., Yoo, D. J., Lee, S. J., Shin, J. N., Park, Y. J., Yoon, H. M., Chun, H. D., Moon, J. K. and Lee, I. B., "Eco-Industrial Park (EIP) development and key technologies for clean production," Kor. Chem. Eng. Res., 43(5), 549 559(2005).

14. Park, H.-S. and Lee, S.-Y., "Outcomes and challenges of eco-industrial park project for Eco-polis Ulsan," Kor. Assoc. Local Govern. Studies Conference Proc., 3, 245 272(2008).

15. Choi, J. S., "Cases of EIP development and implications to industrial complex development of Korea," J. Environ. Policy Administrat., 6(2), 131 161(1998).

16. Lee, K. H., "Eco-industrial park development for clean production," News Informat. Chem. Eng., 20(6), 699 704(2002).

17. Lee, J.-J., Choi, J.-S., Lee, S.-M. and Park, C.-S., "A study on driving strategies and directions for development of ecoindustrial park in Korea," Kor. Planners Assoc., 38(3), 203 220(2003).

18. Doyle, B., Martin, S. A., Weitz, K. A., Cushman, R. A., Sharma, A., Lindrooth, R. C. and Moran, S. R., "Eco-industrial parks: A case study and analysis of economic, environmental, technical, and regulatory issues," Office of Policy, Planning and Evaluation, USEPA, Washington, DC, USA(1996).

19. Kong, H. O. and Ko, J. C., "The improving direction of Korean eco-industrial park construction project," J. Kor. Oil Chemist's Soc., 28(4), 418 430(2011).

20. Korea Industrial Complex Corporation, "Eco industrial park $1^{\text {st }}$ phase 5 year report,"(2010).

21. Park, H.-S., "National eco industrial park project implementation status and considerations," Consultation meeting report of a study on the construction plan of asia network for waste exchange for activating resources recycling(2006).

22. Ministry of Trade, Industry and Energy, "Enforcement rule of the act on the promotion of the conversion into environmentfriendly industrial structure," Act No. 12154, Jan.1(2014).

23. Korea Industrial Complex Corporation, "Study on the midlong term master plan for the 3rd phase of Korea eco industrial park,"(2013).

24. Korea Industrial Complex Corporation, "Introduction of eco industrial park,"(2013).

25. Korea National Cleaner Production Center, "Eco industrial park handbook,"(2004). 